\title{
Comparative Efficacy of Different Oil Cakes as a Soil Amendments against M. Incognita on the Yield of Soyabean
}

\author{
Kaushal Kumar Mishra, Praveen Kumar Pandre* \\ Govt. PG College Shajapur, *Govt. S.S.P. College Waraseoni, (M.P.) India
}

\begin{abstract}
The root knot nematode Meloidogyne incognita infest soyabean (Glycine max) along with other vegetable and Leguminous crops causes serious reduction in the growth and yield of crops. The experiment were carried out as a soil amendment with neem cake, mustard cake and castor cake at the rate of 5, 10, $15 \mathrm{gm} /$ pot and found that all the oil cake superior over untreated control but neem cake $15 \mathrm{gm} /$ pot provide best result to increase yield of soyabean crops and reduce the number of second stage juvenile J2 of M.incognita and number of galls in the roots of soyabean.
\end{abstract}

Keyword: M.incognita, Oil Cake, Soyabean.

\section{INTRODUCTION}

Meloidogyne incognita is root knot nematode which infest wide variety of crops and causes huge loss in production. They are obligate parasites that causes significant damage to a broad range of host plants. About 2000 plants are susceptible to infection by root knot nematodes (Hussey \& Janssen 2002). It infect vegetable crops, agricultural crops, flowering plants and even grasses ie almost all the families of diacots and monocots and limiting world agricultural productivity. Soyabean (Glycine max) is a high protein contain leguminous crop also infested by M.incognita which reduce the yield of crop. The experiment were carried out to determine the efficacy of different oil cakes as a soil amendments to reduce the effect of M.incognita and increase the yield of Soyabean crops.

\section{Material Method}

The experiment was carried out in earthen pot to determine the efficacy of Neem cake, Mustard cake and Castor cake at the rate of 5, 10, 15, gm/pot against Meloidogyne incognita. $2 \mathrm{~kg}$ sterilized soil filled in disinfested earthen pots with finely powdered oil cake as per doses mentioned above. These pots were exposed for two weeks to allow decomposition of oil cakes before sowing. The seeds of soyabean were sown in each pot after 15 days of soil amendment. One week old seedlings were the recommended inoculated with $2000 \mathrm{~J} 2 /$ pot. Agronomic practices were adopted through out the experimentation. Each treatment including untreated checks were replicated three times. Three months after sowing the plants were depotted, washed and observations recorded were subjected to statistical analysis.

\section{RESUlT}

The comparison of different doses of all the oil cakes were based on the value of three replication of test plants. Further, the comparative trends emerging from ANOVA were substantiated by the evaluation of efficiency of all three oil cakes in terms of growth parameters. The tool of Critical Difference (CD) was employed. The mean values of the three replicates have been mentioned in the parenthesis in the foregoing text.

\subsection{Effect of Number of Pods}

All the treatments of oil cakes were significantly superior over untreated control (5.00) except 5 $\mathrm{gm} /$ pot dosage of castor cake (5.00 gm) and $5 \mathrm{gm} /$ pot dosage of Mustard cake (5.00). The pots applied with $15 \mathrm{gm} /$ pot dosage of Neem cake produce maximum number of pods (16.00). CD5\%=0.832. Fig1 
Kaushal Kumar Mishra \& Praveen Kumar Pandre

\begin{tabular}{|c|c|c|c|c|c|}
\hline \hline SOURCE & DF & SS & MS & FCAL & FTAB \\
\hline REP & 2 & 301.636 & 150.818 & 474.000 & 3.1 \\
\hline VARIETIES & 10 & 742.909 & 74.291 & 233.486 & 2.32 \\
\hline ERROR & 20 & 6.364 & 0.318 & & \\
\hline SEM= & 32 & 1050.909 & & & 0.832 \\
\hline
\end{tabular}

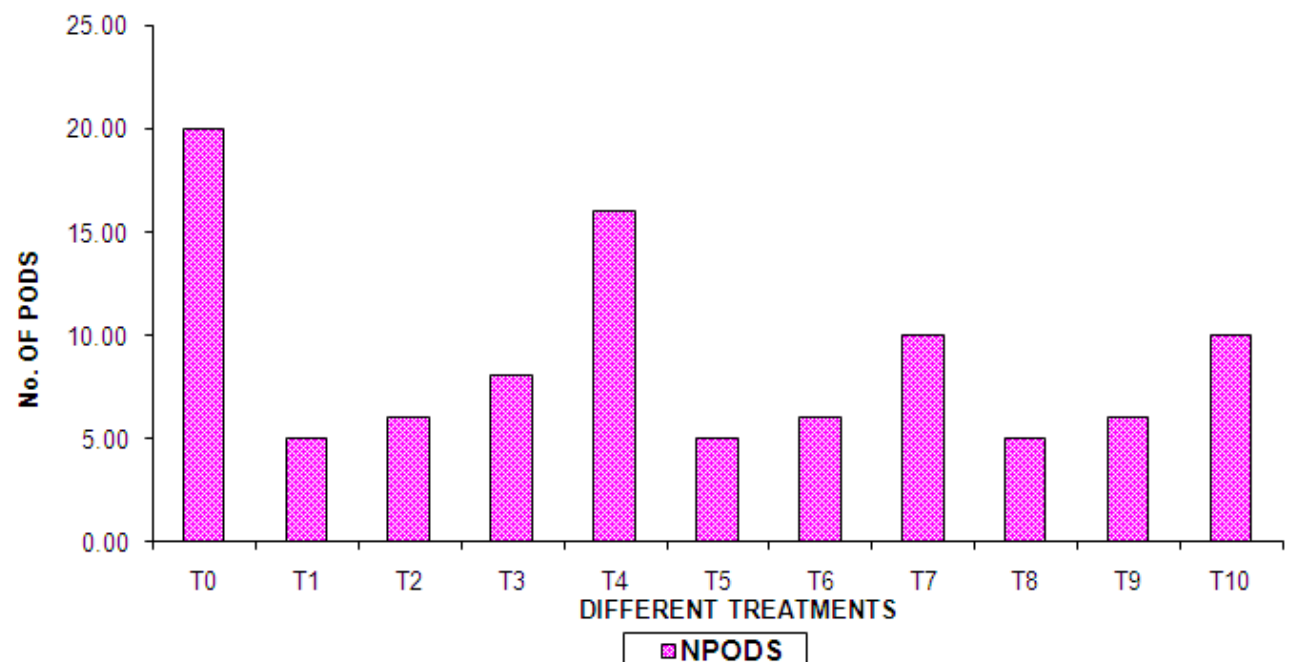

Fig1. Efficacy of different oil cakes - no of pods

\subsection{Weight of Pods}

The result of AVOVA pertaining to the weight of pods revealed that $15 \mathrm{gm} /$ pot dose was efficient to increase the weight of pods. The order of their efficacy was Neem cake $(17.80 \mathrm{gm})>$ Castor cake $(11.50 \mathrm{gm})>$ Mustard cake $(10.60 \mathrm{gm})$. The pods of minimum weight were recorded at the doses of $5 \mathrm{gm} /$ pot mustard cake over untreated control $(6.40 \mathrm{gm})$. CD5\%=1.116. Fig-2

\begin{tabular}{|c|c|c|c|c|c|}
\hline SOURCE & DF & SS & MS & FCAL & FTAB \\
\hline REP & 2 & 276.545 & 138.273 & 241.429 & 3.1 \\
\hline VARIETIES & 10 & 933.901 & 93.930 & 163.062 & 2.32 \\
\hline ERROR & 20 & 11.455 & 0.573 & & \\
\hline & 32 & 1221.901 & & & \\
\hline SEM $=$ & 0.378 & SE $=$ & 0.535 & CD5\%= & 1.116 \\
\hline
\end{tabular}

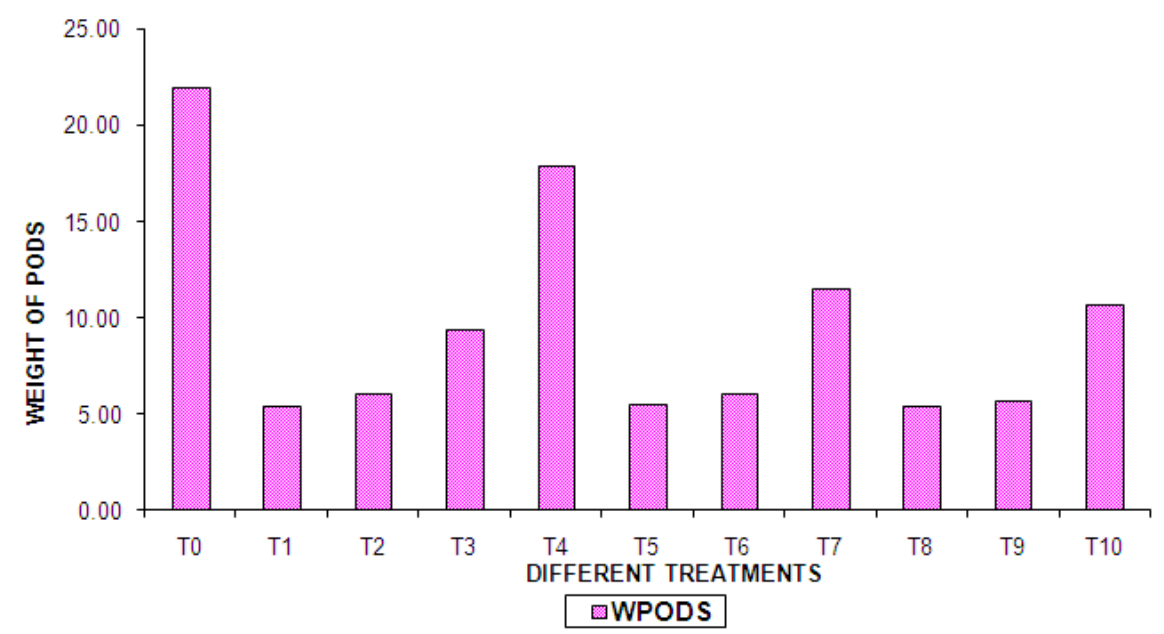

Fig2. Efficacy of different oil cakes-weight of pods

\subsection{Fresh Seed Weight}

The data on the fresh seed weight of Potted plants showed that $15 \mathrm{gm} /$ pot dosage of Neem cake was more effective $(9.40 \mathrm{gm})$ followed by $15 \mathrm{gm} /$ pot dosage of Castor cake $(6.80 \mathrm{gm})$ and $15 \mathrm{gm} / \mathrm{pot}$ dosage of Mustard cake $(6.20 \mathrm{gm})$. The least effective dose was $5 \mathrm{gm} /$ pot Castor cake $(2.70 \mathrm{gm})$ over untreated control (2.60 gm).CD5\% $=1670$. Fig-3 
Comparative Efficacy of Different Oil Cakes as a Soil Amendments against M. Incognita on the Yield of Soyabean

\begin{tabular}{|c|c|c|c|c|c|}
\hline \hline SOURCE & DF & SS & MS & FCAL & FTAB \\
\hline REP & 2 & 83.697 & 41.848 & 32.648 & 3.1 \\
\hline VARIETIES & 10 & 267.457 & 26.746 & 20.865 & 2.32 \\
\hline ERROR & 20 & 25.636 & 1.282 & & \\
\hline SEM= & 32 & 376.791 & & & 1.670 \\
\hline
\end{tabular}

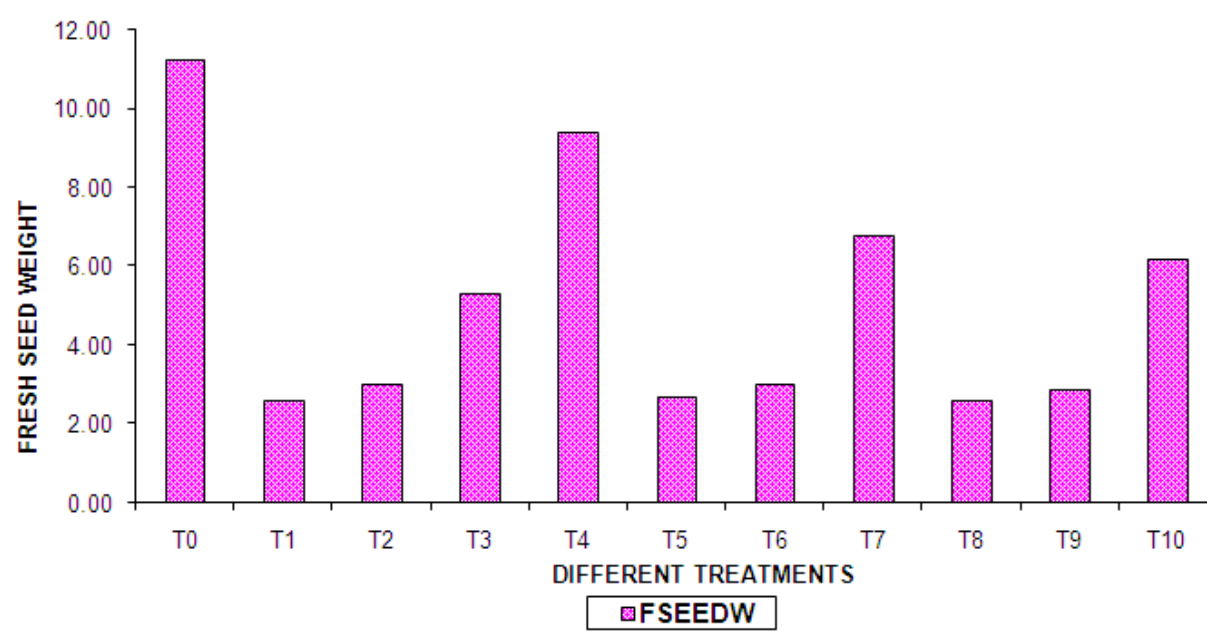

Fig3. Efficacy of different oil cakes-fresh seed weight

\subsection{Effect on Dry Seed Weight}

All the treatment of oil cakes were significantly superior over untreated control except $5 \mathrm{gm} /$ pot dose of mustard cake $(1.40 \mathrm{gm})$ which was at par with untreated control $(1.40 \mathrm{gm})$. The effectiveness of 15 $\mathrm{gm} /$ pot dosage of different oil cakes were as follows: Neem cake (3.57 gm) > Mustard cake (3.00 gm) $>$ Castor cake $(2.90 \mathrm{gm}) . \mathrm{CD} 5 \%=0.871$. Fig -4

\begin{tabular}{|c|c|c|c|c|c|}
\hline SOURCE & DF & SS & MS & FCAL & FTAB \\
\hline REP & 2 & 35.697 & 17.848 & 51.217 & 3.1 \\
\hline VARIETIES & 10 & 32.296 & 3.230 & 9.268 & 2.32 \\
\hline ERROR & 20 & 6.970 & 0.348 & & \\
\hline SEM= & 32 & 74.693 & & & 0.871 \\
\hline
\end{tabular}

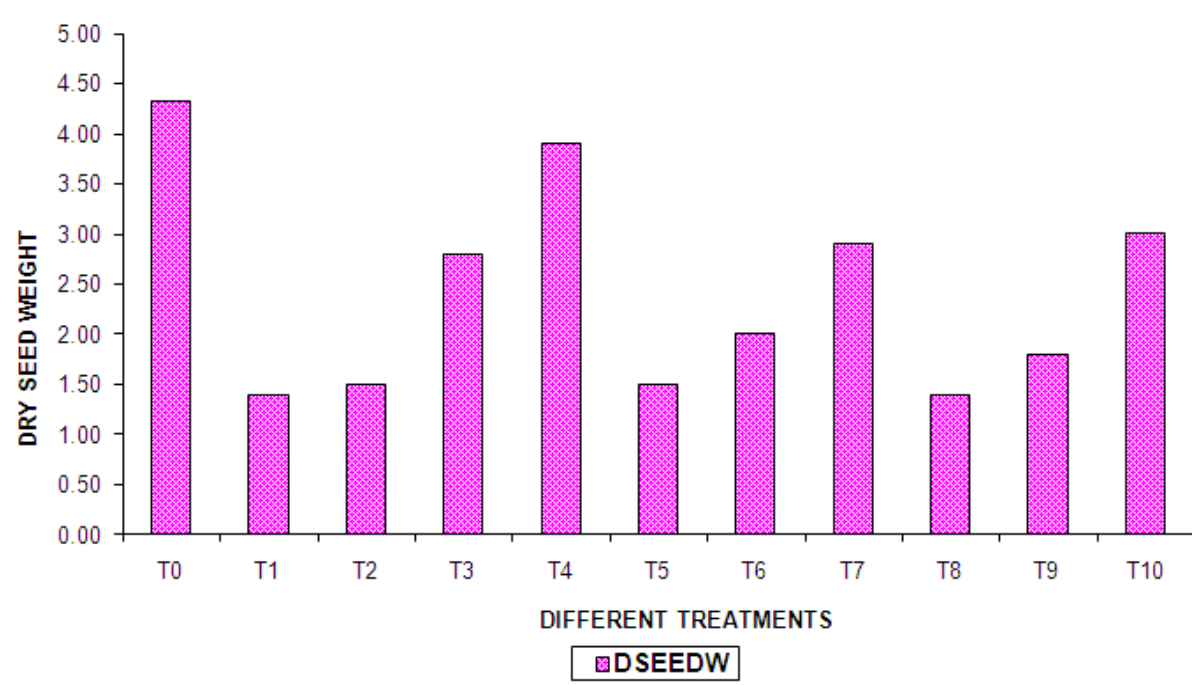

Fig4. Efficacy of different oil cakes-dry seed weight

\subsection{Effect on Number of $I_{2} / \mathrm{ml}$ Soil}

The oil cakes at $15 \mathrm{gm} /$ pot exhibited highest adverse effect of their nematicidal effect was under. Neem cake (6.00)> Mustard cake (15.00)> Castor cake (17.33). The non-effective dose was 5gm/pot mustard cake (50.33) over untreated control (48.00). CD5\%=4.764. Fig-5 
Kaushal Kumar Mishra \& Praveen Kumar Pandre

\begin{tabular}{|c|c|c|c|c|c|}
\hline \hline SOURCE & DF & SS & MS & FCAL & FTAB \\
\hline REP & 2 & 38.061 & 19.030 & 1.825 & 3.1 \\
\hline VARIETIES & 10 & 10569.394 & 1056.939 & 101.334 & 2.32 \\
\hline ERROR & 20 & 208.606 & 10.430 & & \\
\hline SEM $=$ & 32 & 10816.061 & & & \\
\hline & 1.615 & SE $=$ & 2.284 & CD5\%= & 4.764 \\
\hline
\end{tabular}

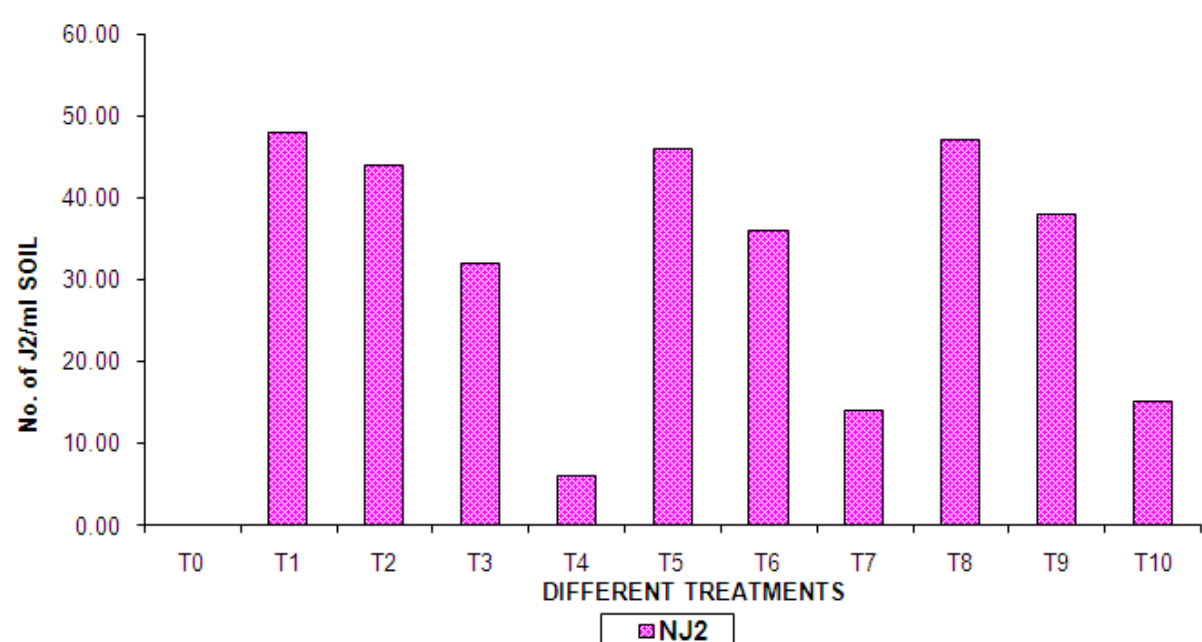

Fig5. Efficacy of different oil cakes-no. of $\mathrm{J} 2 / \mathrm{ml}$ soil

\subsection{Effect on Number of Galls}

The nematicidal efficacy of oil cake was found to be highest at $15 \mathrm{gm} /$ pot dosage. The order of their efficiency was Neem cake (4.00) > Mustard cake (11.00) > Castor cake (13.00). The minimum reduction in number of galls was noticed at $5 \mathrm{gm} /$ pot , Castor cake (76.00) over untreated control (121.00).CD5\%=2.535. Fig-6

\begin{tabular}{|c|c|c|c|c|c|}
\hline SOURCE & DF & SS & MS & FCAL & FTAB \\
\hline REP & 2 & 428.909 & 214.455 & 72.585 & 3.1 \\
\hline VARIETIES & 10 & 42782.182 & 4278.218 & 1448.012 & 2.32 \\
\hline ERROR & 20 & 59.091 & 2.955 & & \\
\hline SEM $=$ & 32 & 43270.182 & & & \\
\hline
\end{tabular}

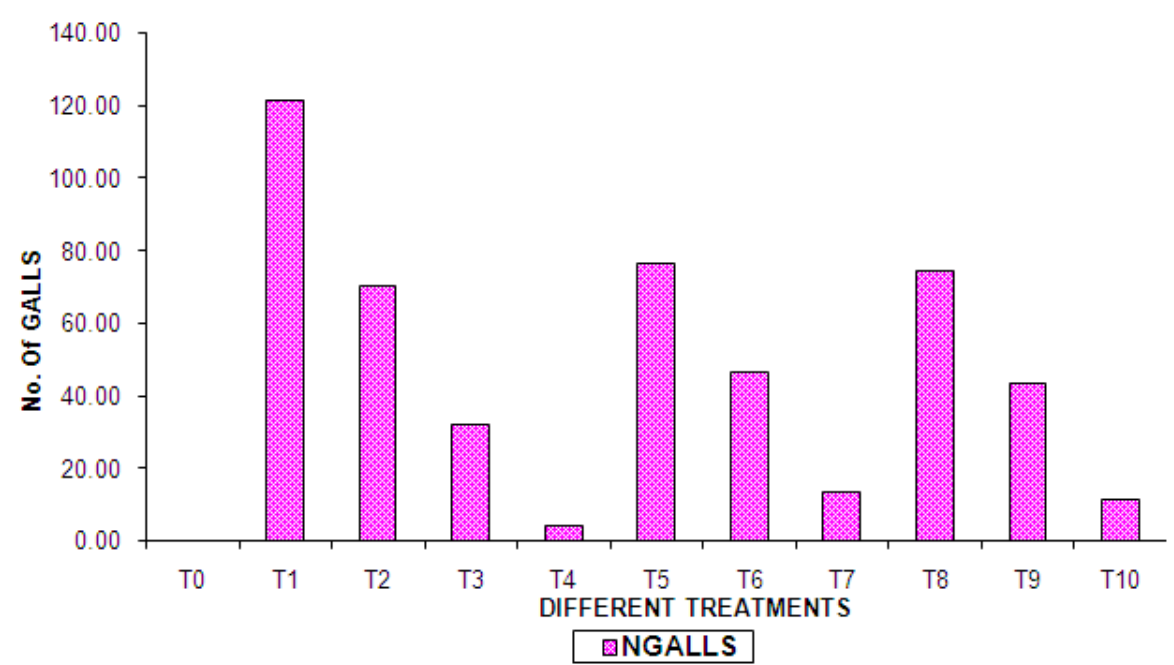

Fig6. Efficacy of different oil cakes-no. of Galls

\section{DisCuSSION}

The experiment illustrated that all the treatment were superior over untreated inoculated control. Application of organic amendments (oil cake) result in the release of plant nutrients which accelerate root development and over all plant growth and thus helping the plants to escape nematode attack. Nematicidal and Nutritive value indicated by organic amendment would have promoted plant growth 
Zaiyd (1977). Result of the present investigation were in conformity with the finding of Mishra and Prasad (1974), Pandey and singh (1990) who had also applied the oil cakes of Neem, castor and mustard in soil and observed a significant increases in plant growth characters and reduced nematodes population of M.incognita, Retylenchulus reniformis and Tylenchorhychus brassicae. Addition of organic amendment also resulted in accumulation of nitrates and ammonia in high concentration, which was highly injurious to several nematodes in soil (Singh \& Sitaramiah 1973). Addition of organic matter to soil as an alternative means of nematode control was also explored by Suhail \& Anvar (2006).

The results of our study suggest that the application of oil cakes can control root knot nematodes effectively thus resulting in increased plant growth. Among the three oil cakes neem cake proved to be the most beneficial followed by mustard and Castor in improving plant growth characters and suppressing nematode population. Mukesh Sehgal et al (2014) reported that caster cake and neem oil combination increase the pod yield in groundnut.

Vaitheeswaran et al. (2005) found that growth was maximum in Neem oil cake treated infected plant of Phaseolus mungo. Manju Meena, S. Bhargava, M.K. Sharma and H.R. Gurjar (2013) reported that leaf extract of neem at $20 \%$ was found to be the best treatment in improving plant growth characters and in reducing nematode population on tomato. Seenivasan, (2010) also found that Neem cake was more efficacious than castor cake in reducing nematode population in medicinal coleus.

\section{REFERENCES}

[1] Hussey, R.S. and Janssen, G.J.W. (2002). Plant resistance to parasitic nematodes. Starr, J.L.; Cook, R. and Bridge, J. (Eds) CAB International. United Kingdom 43-70pp.

[2] Meena, Manju, Bhargava, S., Sharma, S.K. and Gurjar, H.R. (2013). Effect of different plant extracts as root dip treatment against $M$. incognita infecting tomato. Indian J. Nematlogy, 43 (1) 106-108.

[3] Mishra, S.D. \& Prasad, S.K. (1973). Indian J. Ent. 35: 104-106.

[4] Mukesh Sehgal, C. Luckose and R.K. Jain (2014). A successful adaptable integrated management technology against root-knot nematode M. arenaria. Indian J. Nematology. 44(1) PP. 101-102.

[5] Pandey, G. and Singh, K.P. (1990). Effect of organic amendments on soil microflora and nematode fauna with special reference to $M$. incognita in Soyabean. New Agriculturist. 1: 6570.

[6] Singh, R.S. and K. Sitaramaiah (1973). Control of plant Parasitic nematodes with organic amendments of soil. Govind Ballabh Pant University of Agriculture and Technology. Research Bulletin No.6, pp.33.

[7] Sreenivasan, N. (2010). Management of root-knot nematode, Meloidogyne incognita with organic amendments in medicinal coleus. Ann. Pl. Protec. Sci. 18 (2: 472-476.

[8] Suhail Anver, (2006). Control of plant parasitic nematodes associated with linseed by oil secakes and ploughing. Indian J. of Nematol. Vol. 36, No.2 pp. 192-194.

[9] Vaitheeswaran, M., S. Mohamed Ibrahim and K. Lakshmi Narasimhan (2005). Organic amendments for the control of root-knot nematode on Phaseolus mungo. Indian Journal of Nematology. Vol. 35, No.2, pp. 112-119.

[10] Zaiyd, M. (1977). Effect of organic soil amendments on incidence of RKN (M. javanica) on Okra plant. Proceeding of Bihar Academy of Agriculture Sciences. 25: 23-26. 